Article

\title{
Lipid Extracts from Caulerpa lentillifera Waste: An Alternative Product in a Circular Economy
}

\author{
Thanyarat Srinorasing ${ }^{1}$, Nattayaporn Chirasuwan ${ }^{1}$, Boosya Bunnag ${ }^{1,2}$ and Ratana Chaiklahan ${ }^{1, *}$ \\ 1 Pilot Plant Development and Training Institute, King Mongkut's University of Technology Thonburi, \\ Bang Khun Thain, Bangkok 10150, Thailand; thanyarat.sri@kmutt.ac.th (T.S.); \\ nattayaporn.chi@kmutt.ac.th (N.C.); boosya.bun@kmutt.ac.th (B.B.) \\ 2 School of Bioresources and Technology, King Mongkut's University of Technology Thonburi, \\ Bang Khun Thain, Bangkok 10150, Thailand \\ * Correspondence: ratana.cha@kmutt.ac.th; Tel.: +66-2470-7483; Fax: +66-2452-3455
}

Citation: Srinorasing, T.;

Chirasuwan, N.; Bunnag, B.;

Chaiklahan, R. Lipid Extracts from

Caulerpa lentillifera Waste: An

Alternative Product in a Circular

Economy. Sustainability 2021, 13, 4491

https://doi.org/10.3390/su13084491

Academic Editors: Adriana Del

Borghi and Marc A. Rosen

Received: 16 February 2021

Accepted: 14 April 2021

Published: 17 April 2021

Publisher's Note: MDPI stays neutral with regard to jurisdictional claims in published maps and institutional affiliations.

Copyright: (c) 2021 by the authors. Licensee MDPI, Basel, Switzerland. This article is an open access article distributed under the terms and conditions of the Creative Commons Attribution (CC BY) license (https:// creativecommons.org/licenses/by/ $4.0 /)$.

\begin{abstract}
Nowadays, a circular economy is one of the main strategies for developing a sustainable economy. The objective of this work was to increase the value of Caulerpa lentillifera waste and use it efficiently as a resource for lipid extraction. A crude lipid yield of approximately $27.69 \%$ of the dry weight was obtained under the following optimized conditions that consisted of a threestage extraction with $15 \mathrm{~min} /$ stage using a ratio of 1:10 $(w / v)$ at room temperature. The crude extracts contained a total fatty acids (TFA) content of approximately $58.60 \%$ of the weight of the extracts, which consisted of 10 types of fatty acids. The proportion of palmitic acid (16:0) as the main component was above $70 \%$ of the TFA content. Moreover, it also contained chlorophylls $a$ and $b$ and carotenoids at approximately $1.77,0.91$, and $0.70 \mu \mathrm{g} / \mathrm{mg}$ of the extract, respectively. The total phenolic and flavonoids content, including 2,2'-azino-bis(3-ethylbenzothiazoline-6-sulfonic acid) and 1,1' - diphenyl-2-picrahydrazyl (ABTS and DPPH, respectively) scavenging activities, showed that the lipid extracts had high potential for antioxidant activity. Moreover, the extracts also demonstrated $\alpha$-glucosidase inhibitory activity with an $\mathrm{IC}_{50}$ value of $8.97 \mathrm{mg} / \mathrm{mL}$. Thus, this extract could be used as an alternative product in a circular economy for preventing diabetes disease.
\end{abstract}

Keywords: Caulerpa lentillifera; lipid; anti-diabetic; circular economy

\section{Introduction}

Caulerpa lentillifera is consumed as food in Asia-Pacific regions, such as Vietnam, the Philippines, Malaysia, Indonesia, and Japan. It has become a famous ingredient for food during the last five years in Thailand. Many farms in the southern region along the coastlines of the Gulf of Thailand produce this food. C. lentillifera is a marine macroalgae known as sea grapes or green caviar. It is rich in minerals, essential amino acids, and fibers and includes several bioactive compounds, such as polysaccharides (20-64\% of dry weight) and lipids (0.86-1.57\% of dry weight) [1-3]. Even though the lipid content is low, many studies have reported that lipids from $C$. lentillifera have potential for a wide variety of biological activities, such as antioxidant, antibacterial, antifungal, and antidiabetic activities [4-7].

Production of Caulerpa and its qualities, such as nutritional value, the erect fronds, and ramuli and stolon fragments depend on salinity, light (irradiance and daylength), and temperature, all of which are parameters that fluctuate seasonally [8-10] and can affect agricultural income because the price of food-grade $C$. lentillifera product depends upon the physical qualities of the fronds, such as their size, length, number of branches, density, and color and/or appearance. Therefore, farmers will select the high-quality fronds for the food market (Figure 1). Normally, around $60-70 \%$ of $C$. lentillifera biomass that is selected is low quality with about $20-25 \%$ that are reused as propagules for the next crop, and then the remaining (useless) biomass becomes landfill on their farms. Moreover, a limitation 
of $C$. lentillifera is its short shelf life (only 5-6 days), after which it is discarded as waste. Due to the fact that $C$. lentillifera is a salt-containing marine alga, the management of waste by landfill may cause high saline levels in the soil. According to a study by Chaiklahan et al. [11], it was found that the nutritional values of $C$. lentillifera waste were not different from food-grade products although the color was yellow-brown. Therefore, the waste could be used as a material for extraction of bioactive compounds, such as polysaccharides and lipids, in order to increase the value of $C$. lentillifera waste and transform poor-quality material to new products with high value-added.
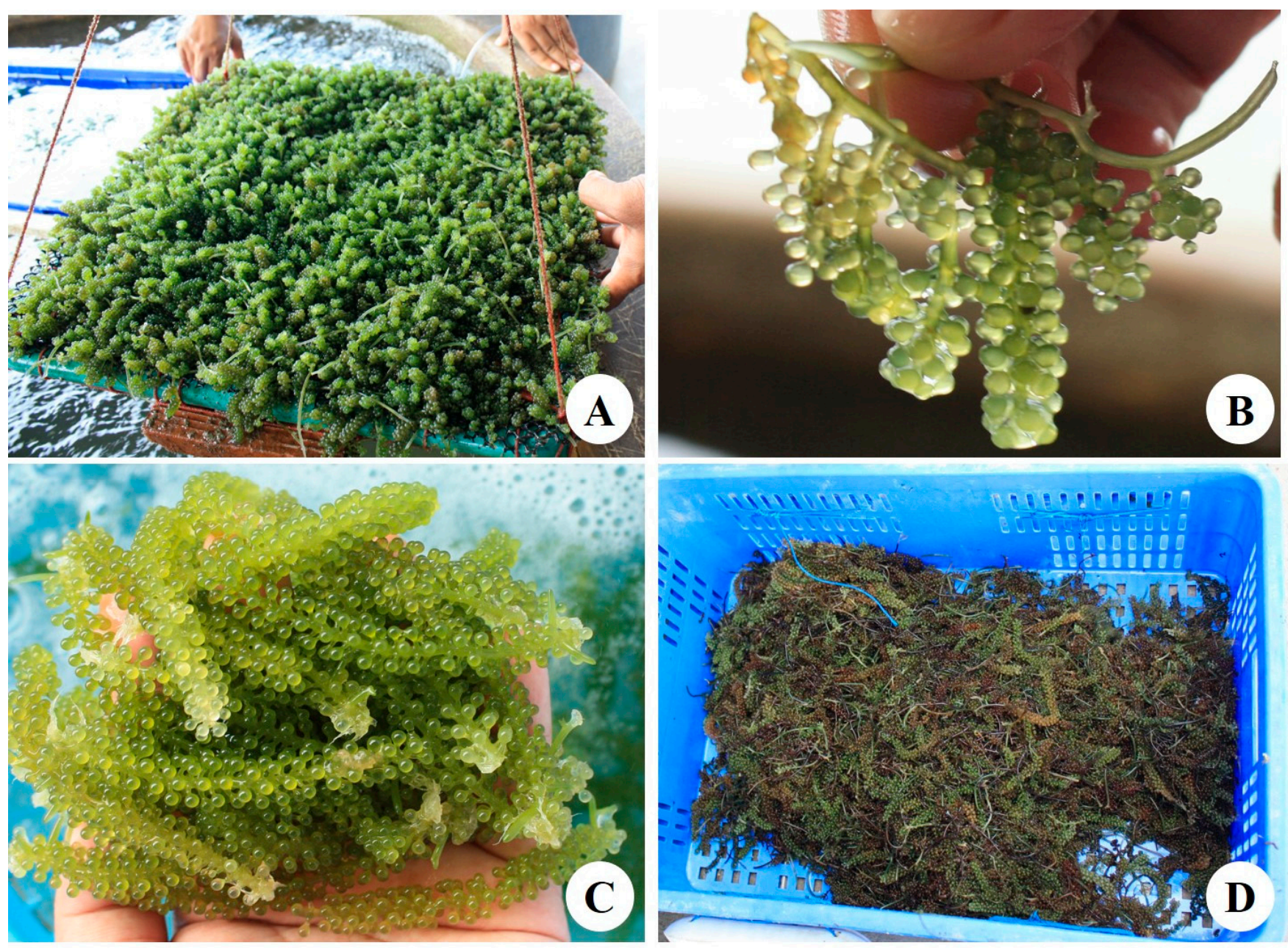

Figure 1. Caulerpa lentillifera products (A,B), food grade (C), and waste grade (D).

Bio-, circular, and green economies (BCG) models play an important role in the economic development of many countries in order to add value to agricultural products, efficiently use resources, and reduce waste to zero. These efforts are a key strategy for sustainable economic development because significant losses and waste in the production processes are becoming a serious nutritional, economical, and environmental problem [12,13]. Large amounts of agro-industrial waste are removed from the production process as undesirable material since these compounds have a great potential for being transformed into energy, bio-based products, or functional compounds, such as antioxidants that provide health benefits because they are cheap sources of these antioxidants [14-16]. Many scientists are researching this concept. For example, Munir et al. [17] extracted bioactive compounds from waste onion skin, and Ferri et al. [16] validated possible routes of using winery waste to produce bioactive substances via two procedures: (1) solvent-based extraction and (2) pressurized liquid extraction, which yielded products with strong antioxidant properties. In addition, our previous study [11] found that the polysaccharide extracts 
from C. lentillifera waste showed potential for preventing diabetes through $\alpha$-glucosidase inhibitory activity.

Natural sources for $\alpha$-glucosidase inhibitors are plants and macroalgae, and many candidates for this inhibitor are secondary metabolites, including alkaloids, flavonoids, phenols, and terpenoids [18-20]. Moreover, nojirimycin and fagomine were the first natural iminosugars to be discovered from a microbe (Streptomyces) and plant (Fagopyrum esculentum) [18] Diabetes mellitus is a very serious, chronic metabolic disorder that is characterized by high blood glucose levels [21]. Type 2 diabetes mellitus (T2DM) is more prevalent than type 1 and affects around $90 \%$ of diabetic patients. This disease is caused by an imbalance between blood sugar absorption and insulin secretion. Carbohydrates are normally converted to glucose by $\alpha$-glucosidase enzymes for later intestinal absorption, which leads to an increase in blood glucose levels. The capability of a drug or diet to delay the production of glucose by inhibiting carbohydrate hydrolyzing enzymes is one of the therapeutic approaches for decreasing hyperglycemia [22,23]. However, Yen et al. [24] reported that $\alpha$-glucosidase inhibitor (AGI) use was associated with higher risks of all-cause mortality and non-cardiovascular deaths in insulin-treated patients with T2DM. Therefore, giving AGIs to insulin-treated patients may not be appropriate.

According to Bhatia et al. [25], methanolic extracts from plant (Cornus capitata) showed potential for the treatment of hyperglycemia. Likewise, Xiancui et al. [19] reported that lipid extracts from macroalgae, such as Rhodomela confervoides (Huds.) Silva, Gracilaria textorii (Suringar) DeToni, Plocamium telfairiae Harv., and Enteromorpha intestinal (L.) Link, showed strong inhibitory activity toward $\alpha$-glucosidase. To increase the value of $C$. lentillifera waste, lipid extraction is an alternative route for new products with high value-added. The aim of this work was to optimize the extraction process by investigating the effects of the sample-to-solvent ratio, extraction time, and repetition number of extractions on the yield of lipid. The characteristics of the lipid extracts and their antioxidant properties were also studied to develop a guideline for applications.

\section{Materials and Methods}

\subsection{Materials}

C. lentillifera was cultivated and collected at Phetchaburi Coastal Aquaculture Research and Development Center in Phetchaburi Province, Thailand. The cultivation, collection, and preparation for C. lentillifera material were described in our previous study [11]. Dried C. lentillifera powder was obtained after drying in a hot-air oven at $65{ }^{\circ} \mathrm{C}$ for $24 \mathrm{~h}$ and milling the product with a blender.

\subsection{Lipid Extraction Conditions}

Ethanol was used as a solvent for lipid extraction because it is safe for applications. To determine the effect of the sample-to-solvent ratio on the lipid yield, dried C. lentillifera powder weighing $30,15,10,7.5$, and $5 \mathrm{~g}$ was added to $150 \mathrm{~mL}$ of ethanol in order to prepare mixtures with solid-to-ethanol ratios of 1:5, 1:10, 1:15, 1:20, and 1:30 $(w / v)$, respectively. The extraction process was performed in a single stage at room temperature for $30 \mathrm{~min}$ under continuous mixing using a stirrer at $300 \mathrm{rpm}$.

To determine the optimum extraction time, a ratio of 1:10 ( $80 \mathrm{~g}$ of dried biomass in $800 \mathrm{~mL}$ of ethanol) was used at room temperature, and extraction times ranged from 15 to $180 \mathrm{~min}$. For investigation of the repetition number of extractions, the extraction was performed using a biomass/ethanol ratio of 1:10 (w/v) for 15 and $30 \mathrm{~min}$ in the first stage. The residue was separated by filtration and then re-extracted with fresh ethanol at each extraction stage (up to six stages).

The lipid solution was separated from the algae residue using filter papers (Whatman no. 4). The solvent in the lipid solution was then removed with a vacuum rotary evapora- 
tion to obtain crude lipids, which contained fatty acids and pigments. The yield of crude lipid extracts was measured as the percentage of dry weight using Equation (1):

Yield $(\%$ dry weight $)=($ weight of lipids $/$ dried sample weight $) \times 100$

\subsection{Analyses}

Lipid content was determined using a mixture of chloroform, methanol, and water $(2.5: 1.25: 1 \mathrm{v} / \mathrm{v} / \mathrm{v})$ following the procedures described by Sato and Murata [26] with slight modifications. For partial purification, the crude lipid sample was dissolved in 30\% methanol/water and then partitioned with hexane. The hexane fraction was collected and evaporated. The aqueous methanol phase was then sequentially partitioned with ethyl acetate and methanol, and each fraction was collected and evaporated.

Total fatty acid (TFA) in the samples was determined using the transesterification protocol proposed by Lapage and Roy [27] with modifications. Lipid extract (50-100 mg) was directly trans-methylated in $2.5 \% \mathrm{HCl}$ in methanol at $85{ }^{\circ} \mathrm{C}$ for 90 min using heneicosanoic acid (C21:0; Sigma-Aldrich) as an internal standard. Fatty acid methyl esters were analyzed with gas chromatography (GC 17-A; Shimadzu, Japan) using capillary columns of fused silica glass $(60 \mathrm{~m} \times 0.25 \mathrm{~mm}, \mathrm{BPX70}$, SGE, USA) and a film thickness of $0.25 \mu \mathrm{m}$. The split ratio was $1: 50$, and the column temperature was initially set at $170{ }^{\circ} \mathrm{C}$, which was increased to $205{ }^{\circ} \mathrm{C}$ at a rate of $1{ }^{\circ} \mathrm{C}$ per minute. The injector and flame ionization detector temperatures were 250 and $260^{\circ} \mathrm{C}$, respectively. Identification was carried out by co-chromatography with authentic standards (Sigma-Aldrich).

Pigments were determined using methanol and measured at 470, 666, and $648 \mathrm{~nm}$ for carotenoids and chlorophylls $a$ and $b$, respectively [28]. Total phenolic content was estimated using the Folin-Ciocalteu reagent, and the absorbance was measured at $765 \mathrm{~nm}$ [29]. The content was calculated based on the standard curve of gallic acid, and the results were expressed as mg gallic acid equivalents (mg GAE) per gram of sample.

Total flavonoids content was determined using the aluminum chloride colorimetric method described by Pallab et al. [30] with slight modifications. The lipid solution was mixed with $1.5 \mathrm{~mL}$ of methanol, $0.1 \mathrm{~mL}$ of $2 \%$ aluminum chloride, and $0.1 \mathrm{~mL}$ of $1 \mathrm{M}$ potassium acetate solution. Distilled water $(2.8 \mathrm{~mL})$ was added, and the solution was mixed well. After a $30 \mathrm{~min}$ incubation period, the absorbance of the reaction mixture was measured at $415 \mathrm{~nm}$. The total flavonoid content was calculated based on the standard quercetin curve, and the results were expressed as mg quercetin equivalents (mg QE) per gram of extract.

DPPH radical scavenging activity was measured using DPPH (Sigma Chemical Co., St. Louis, MO, USA) with a modification of the method reported by Li et al. [31]. Briefly, $0.1 \mathrm{mM}$ DPPH solution in ethanol was added to the lipid solution. After incubation in the dark for $30 \mathrm{~min}$, the absorbance was measured at $517 \mathrm{~nm}$. In the same way, ABTS decolorization scavenging activity was measured using ABTS (Sigma Chemical Co., St. Louis, MO, USA) following the procedure reported by Zheleva-Dimitrova et al. [32] with some modifications. $\mathrm{ABTS}^{+}$radicals were prepared by mixing $7 \mathrm{mM}$ ABTS in water and $2.45 \mathrm{mM}$ potassium persulfate $(1: 1, v / v)$ and kept in the dark at room temperature for $16 \mathrm{~h}$ before use. The ABTS solution was then diluted with methanol to obtain an absorbance of 0.700 at $734 \mathrm{~nm}$. Next, $2 \mathrm{~mL}$ of ABTS. solution was added to the lipid solution. After incubation in the dark for $7 \mathrm{~min}$, the absorbance was measured at $734 \mathrm{~nm}$. Trolox was used as a standard for both DPPH and ABTS.

The $\alpha$-glucosidase inhibitory activity of the lipid extracts was determined using the procedures described by Alam et al. [33] with some modifications. The formation of $p$-nitrophenol that resulted from the cleavage of $p$-nitrophenyl- $\alpha$-D-glucopyranose was estimated for the evaluation of $\alpha$-glucosidase inhibitory activity. The enzyme, $\alpha$ glucosidase (Sigma-Aldrich, Steinheim, Germany), and the substrate, $p$-nitrophenyl- $\alpha$-Dglucopyranose (Sigma-Aldrich, Buchs, Switzerland), were dissolved in $50 \mathrm{mM}$ phosphate buffer ( $\mathrm{pH}$ 6.5) and incubated at $26.8^{\circ} \mathrm{C}$ for $15 \mathrm{~min}$. The optical densities were read at $415 \mathrm{~nm}$ in a multi-detection micro-plate reader, and acarbose was used as a standard. 


\subsection{Statistics}

The results are expressed as the mean \pm standard deviation (SD) of triplicate datasets from independent experiments. Statistical analysis was performed through an analysis of variance (ANOVA) with a confidence level of $95 \%(p<0.05)$.

\section{Results and Discussion}

\subsection{Optimum Conditions for Lipid Extraction}

\subsubsection{Sample-to-Solvent Ratio}

The results showed that an increase in volume of ethanol used for extraction led to an increase in the lipid yield from $7.7 \%$ to $16.9 \%$ of dry weight (Figure 2). Although the lipid yield from a ratio of 1:30 $(w / v)$ was highest, a high volume of ethanol may not be economically feasible based on the price and energy input needed for evaporation. The lipid yield from a ratio of 1:10 $(w / v)$ was $42.8 \%$ higher than that at 1:5 $(w / v)$, but no significant differences between ratios of 1:10 $(w / v)$ and 1:15 $(w / v)$ or ratios of 1:15 $(w / v)$ and 1:20 $(w / v)$ were observed. The lipid yield from a ratio of 1:20 $(w / v)$ was only $28 \%$ higher than that of a ratio of 1:10 $(w / v)$, but twice the volume of ethanol was needed for extraction. Hence, a ratio of 1:10 $(w / v)$ was considered a suitable extraction condition based on the lipid yield and the volume of solvent.

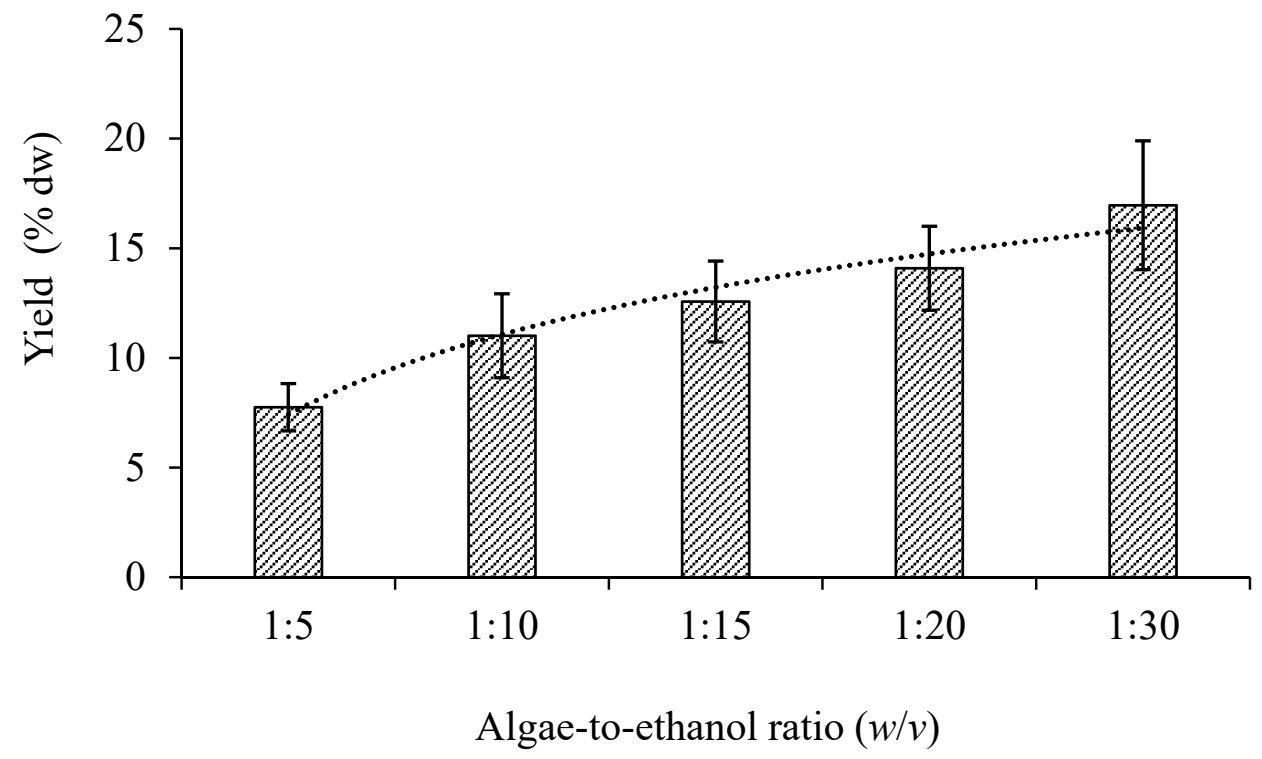

Figure 2. Effect of sample-to-solvent ratio on lipid yield.

\subsubsection{Extraction Time}

The lipid yield was approximately $13-15 \%$ of the dry weight when the extraction was performed with a ratio of 1:10 $(w / v)$ at room temperature for 15 to $180 \mathrm{~min}$ (Figure 3). Although the extraction times of 30 to 120 min showed no differences in the lipid yield, the lipid yield at $15 \mathrm{~min}$ (13.0\% of dry weight) was significantly lower than at $45 \mathrm{~min}(14.0 \%$ of dry weight). Consequently, extraction times of 15 and $30 \mathrm{~min}$ were selected for further investigations of the extraction process. 


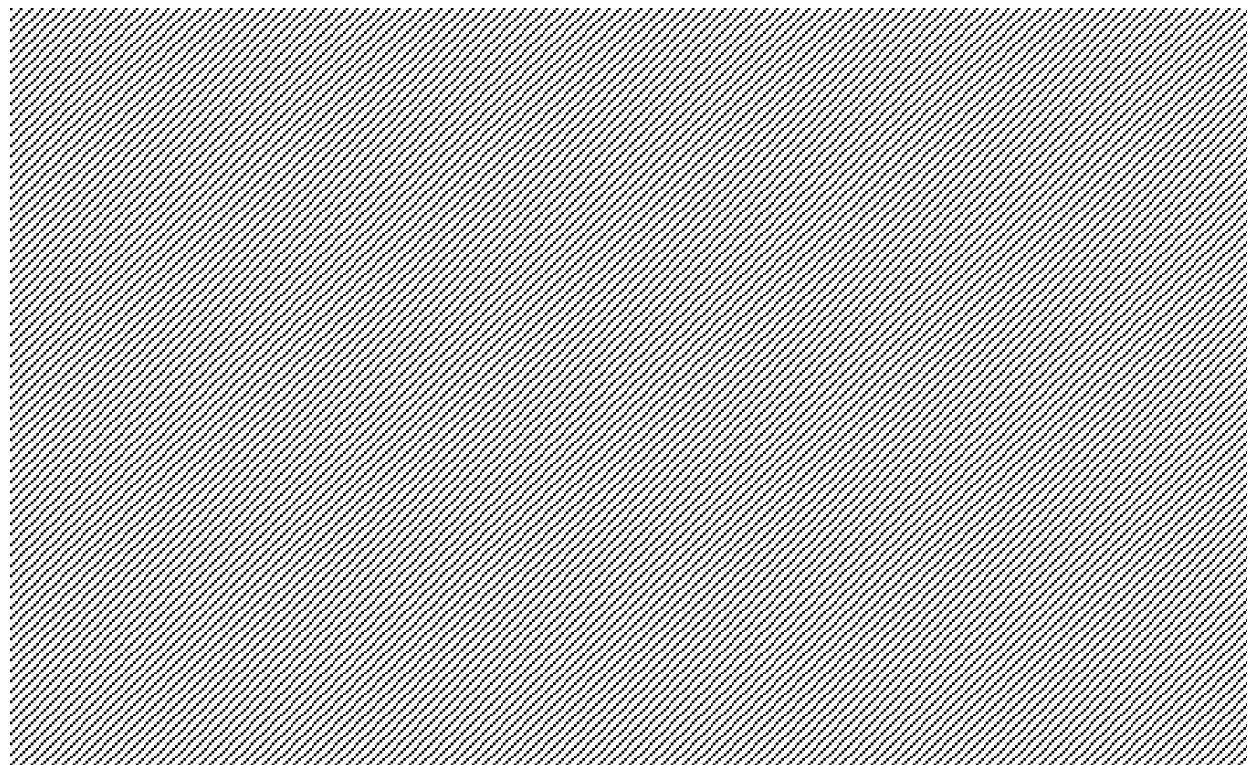

Figure 3. Effect of extraction time on lipid yield.

\subsubsection{Repetition Number of Extractions}

The results showed that the lipid yields at 15 and $30 \mathrm{~min}$ for the first extraction (a single stage) were approximately $16.6 \%$ and $17.2 \%$ of the dry weight. These values decreased by $50 \%$ and $75 \%$ in the second and third extractions, and after that, the lipid yield was around $2 \%$ of the dry weight (Figure 4 ). The lipid extract resembled a gummy solid rather than dried power, which may have resulted in slightly higher lipid yields in this experiment. When total time of extraction, total volume of ethanol, and total lipid yields were considered, it was found that the lipid yield of two-stage and three-stage extractions increased by around $48 \%$ and $70 \%$, respectively, compared to a single-stage extraction (Table 1).

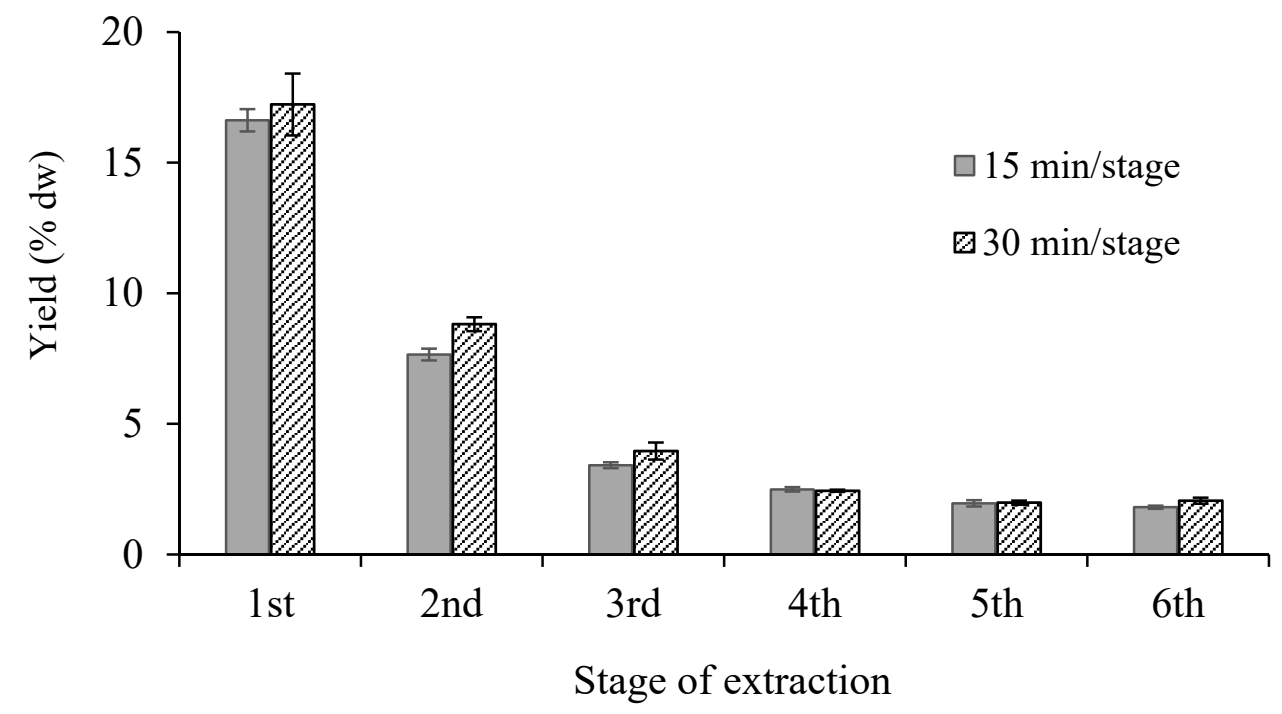

Figure 4. Effect of number of extractions on lipid yield. 
Table 1. Lipid yields under different conditions.

\begin{tabular}{ccccccc}
\hline \multirow{2}{*}{$\begin{array}{c}\text { Number } \\
\text { of Stage }\end{array}$} & \multicolumn{2}{c}{ Total Time of Extraction (min) } & Total Volume of Ethanol (mL) * & \multicolumn{2}{c}{ Total Yield (\% dw) } \\
\cline { 2 - 6 } & $\mathbf{1 5}$ & $\mathbf{3 0}$ & $\mathbf{1 5}$ & $\mathbf{3 0}$ & $\mathbf{1 5}$ & $\mathbf{3 0}$ \\
\hline 1 & 15 & 30 & 150 & 150 & 16.62 & 17.23 \\
2 & 30 & 60 & 300 & 300 & 24.28 & 26.04 \\
3 & 45 & 90 & 450 & & 27.69 & 30.00 \\
4 & 60 & & 600 & & 30.18 \\
\hline
\end{tabular}

* Each stage used $150 \mathrm{~mL}$ of ethanol.

When a three-stage extraction and equal volumes of ethanol $(450 \mathrm{~mL})$ were used, the lipid yield at the $15 \mathrm{~min} /$ stage (27.69\% of dry weight) was slightly lower (10\% less) than that extracted at the $30 \mathrm{~min} /$ stage $(30.00 \%$ of dry weight), but the total extraction time was reduced by $50 \%$ (from 90 to $45 \mathrm{~min}$ ). Therefore, the three-stage extraction with the $15 \mathrm{~min} /$ stage was considered a suitable condition based on the short time for extraction.

\subsection{Compositions of Lipid Extracts}

The crude lipid was extracted using ethanol as a solvent, and therefore, the lipid yields were higher than the lipid content in the raw material (C. lentillifera: around $2 \%$ of dry weight) [11]. The lipid content in the algae material was determined using a mixture of chloroform, methanol, and water, and after homogenization, more chloroform and water were added to obtain two separate phases: (1) a methanol/water phase (upper phase) and (2) a chloroform phase (lower phase). The total lipids remained in the chloroform, and the polar molecules (proteins, salt, and impurities) partitioned into the methanol/water phase. Moreover, the intermediate fluff layer was withdrawn and discarded, resulting in low impurities in the lipid extracts.

To demonstrate the reason, the crude lipid was re-extracted following the method of Sato and Murata [26] using the same mixture of solvents. The result showed that the lipid yield decreased from $27.69 \%$ to $3.13 \%$ of the dry weight (Figure 5). Furthermore, the crude lipid was also partially purified by liquid-liquid partition using solvents of polarity (hexane 0.1 , ethyl acetate 4.4 , and methanol 5.1) to obtain the hexane-, ethyl acetate-, and methanol-soluble fractions, respectively, as shown in Figure 5. Most of the lipid was dissolved in the ethyl acetate fraction, which accounted for $82.1 \%$ of the total lipid, whereas the proportions of lipid in hexane and methanol were $0.8 \%$ and $17.1 \%$, respectively.

Li et al. [34] reported that the ethyl acetate-soluble fraction of crude ethanol extract from $C$. recemosa exhibited the strongest antioxidant activity because the phenolic compounds of medium polarity and antioxidant capacity were distributed in this fraction. Similarly, Chirasuwan et al. [35] also found that sulphoquinovosyl diacylglycerol (SQDG), an active antiviral agent against herpes simplex virus type 1, was distributed in the ethyl acetate-soluble fraction of the crude lipid from Spirulina platensis. The polarity of ethanol is 4.3 , which is almost the same as that of ethyl acetate and chloroform (4.4 and 4.1, respectively). Therefore, it was expected that lipid extract from C. lentillifera waste would contain bioactive compounds and present an antioxidant capacity.

The lipid extracts contained $58.60 \%$ TFA by weight, which consisted of 10 types of fatty acids. Palmitic acid (16:0) was a major component that accounted for around $74.48 \%$ of the TFA and resulted in a high proportion of $82.56 \%$ saturated fatty acids (SFA). The proportions of monounsaturated and polyunsaturated fatty acids (MFA and PFA, respectively) were approximately $12.68 \%$ and $3.09 \%$, respectively (Table 2 ). This result corresponded to those of Ratana-arporn and Chirapart [1], who reported that C. lentillifera harvested from Phetchaburi Province, Thailand, contained palmitic acid $(67.83 \%)$ as a main component. 


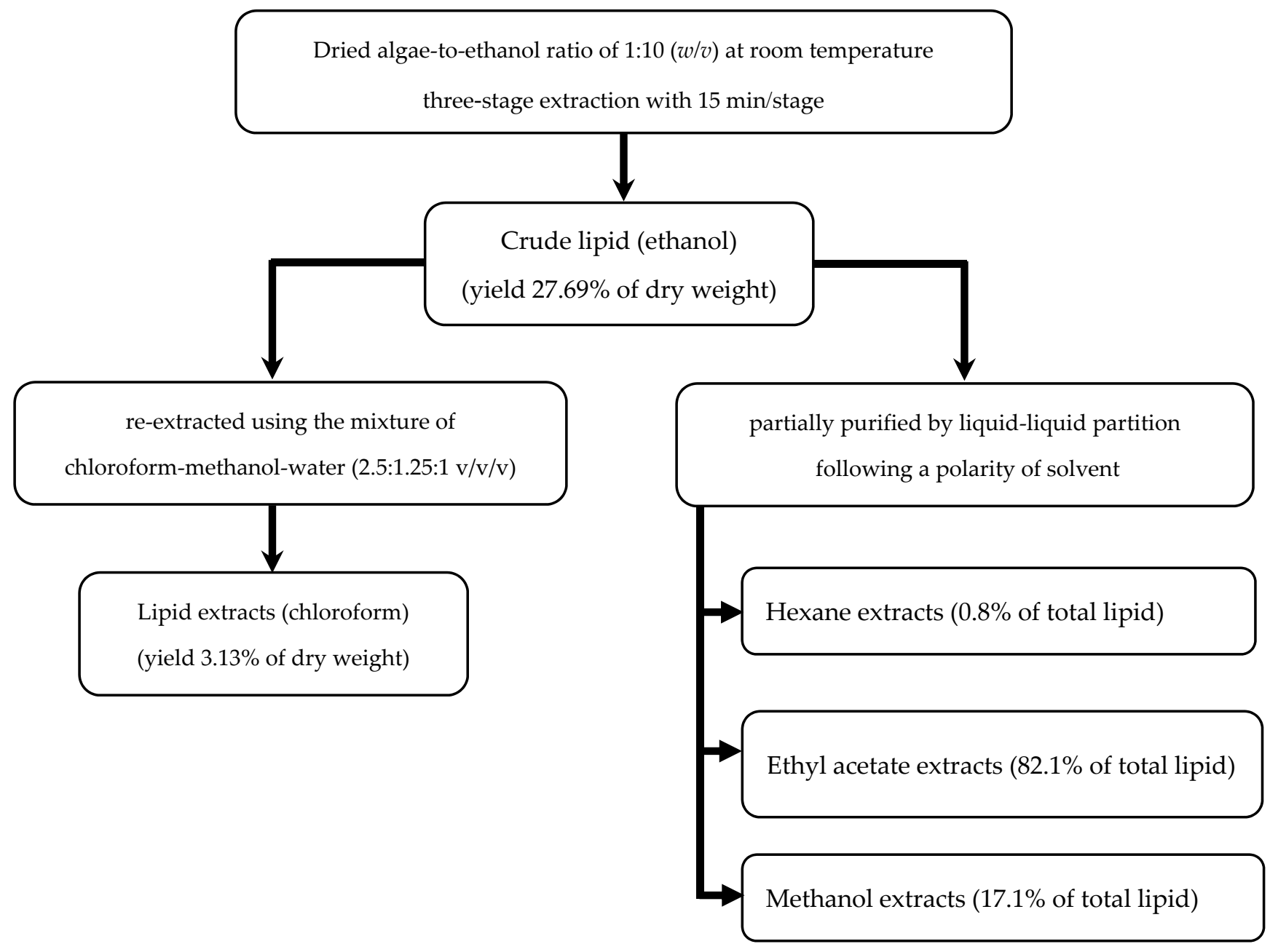

Figure 5. Diagram for purification of lipid extracts.

Table 2. Composition of lipid extracts.

\begin{tabular}{cc}
\hline Compositions & Value \\
\hline Chlorophyll $a(\mu \mathrm{g} / \mathrm{mg}$ of extract) & $1.77 \pm 0.25$ \\
Chlorophyll $b(\mu \mathrm{g} / \mathrm{mg}$ of extract) & $0.91 \pm 0.09$ \\
Carotenoids $(\mu \mathrm{g} / \mathrm{mg}$ of extract) & $0.70 \pm 0.09$ \\
Total fatty acid (TFA; \% weight of lipid extract) & $58.60 \pm 4.95$ \\
Fatty acid compositions (\% mol.) & \\
Myristic acid (14:0) & $4.89 \pm 0.36$ \\
Palmitic acid (16:0) & $74.48 \pm 3.24$ \\
Palmitoleic acid (16:1n7) & $6.82 \pm 0.38$ \\
Stearic acid (18:0) & $2.50 \pm 0.28$ \\
Vaccenic acid (18:1n7) & $3.03 \pm 0.28$ \\
Oleic acid (18:1n9) & $2.92 \pm 0.39$ \\
Linoleic acid (18:2) & $2.69 \pm 0.38$ \\
Linoleic acid (18:3) & $0.93 \pm 0.13$ \\
Arachidonic acid (20:4) & $0.95 \pm 0.09$ \\
Eicosapentaenoic acid (20:5) & $1.01 \pm 0.34$ \\
Saturated fatty acids (SFA) & $82.56 \pm 2.37$ \\
Monounsaturated fatty acids (MFA) & $12.68 \pm 0.44$ \\
Polyunsaturated fatty acids (PFA) & $3.09 \pm 0.69$ \\
\hline
\end{tabular}

Stearic acid (18:0) and palmitoleic acid (16:1) accounted for 11.1\% and 6.08\% of the TFA, respectively. However, the content of fatty acid and distribution of SFA, MFA, and PFA 
depend on seasonal changes [36]. In addition, the crude lipid also contained chlorophylls $a$ and $b$ and carotenoids, accounting for $1.77,0.91$, and $0.70 \mu \mathrm{g} / \mathrm{mg}$ of the extracts, respectively.

\subsection{Antioxidant Properties and Applications}

Antioxidant activity can be determined both quantitatively and qualitatively. Total phenolic and flavonoid contents were tested in the qualitative analysis using a colorimetric assay. The crude lipid extracts from $C$. lentillifera waste contained total phenolic and flavonoid contents of around $2.07 \mathrm{mg}$ GAE/g sample and $5.40 \mathrm{mg}$ QE/g sample, respectively. These values increased to $17.46 \mathrm{mg} \mathrm{GAE} / \mathrm{g}$ sample and $55.48 \mathrm{mg} \mathrm{QE} / \mathrm{g}$ sample, respectively, when the sample was purified lipid (ethyl acetate fraction; Table 3).

Table 3. Antioxidant properties of lipid extracts.

\begin{tabular}{ccc}
\hline Characteristic & Crude Lipid & Purified Lipid \\
\hline Total phenolic $(\mathrm{mg}$ GAE/g sample) & $2.07 \pm 0.34$ & $17.46 \pm 2.24$ \\
Total flavonoids $(\mathrm{mg}$ QE $/ \mathrm{g}$ sample) & $5.40 \pm 0.76$ & $55.48 \pm 7.78$ \\
$\mathrm{IC}_{50}$ ABTS $(\mathrm{mg} / \mathrm{mL})$ & $1.67 \pm 0.09$ & $0.21 \pm 0.06$ \\
$\mathrm{IC}_{50} \mathrm{DPPH}(\mathrm{mg} / \mathrm{mL})$ & $3.55 \pm 0.53$ & $0.43 \pm 0.11$ \\
$\mathrm{IC}_{50} \alpha$-glucosidase $(\mathrm{mg} / \mathrm{mL})$ & $8.97 \pm 0.19$ & Not determined \\
\hline
\end{tabular}

$\mathrm{IC}_{50} \mathrm{ABTS}$ and DPPH of trolox were 0.036 and $0.515 \mathrm{mg} / \mathrm{mL}$, respectively. $\mathrm{IC}_{50} \alpha$-glucosidase of acarbose was $0.28 \mathrm{mg} / \mathrm{mL}$.

Nguyen et al. [3] reported that the ethanolic extract from C. lentillifera contained a total phenolic content of approximately 1.3-2.04 mg GAE/g sample. Similarly, Yap et al. [37] found that methanolic extracts from $C$. lentillifera contained a total phenolic content of $4.52 \mathrm{mg}$ GAE/g sample and a total flavonoid content of $4.93 \mathrm{mg} \mathrm{QE} / \mathrm{g}$ sample, whereas extracts from C. racemosa contained total phenolic and total flavonoid contents of $10.33 \mathrm{mg}$ GAE/g sample and $24.52 \mathrm{mg} Q \mathrm{QE} / \mathrm{g}$ sample, respectively. Osuna-Ruiz et al. [38] found that methanol extracts of $C$. sertularioides contained total phenolic and total flavonoid contents of $0.68 \mathrm{mg}$ GAE/100 mg sample and $14.6 \mathrm{mg}$ QE/g sample, respectively. Tanna et al. [39] reported that aqueous-methanol extracts of Caulerpa spp. had total phenolic contents of around 23.8 to $29.2 \mathrm{mg} \mathrm{GAE} / \mathrm{g}$ sample and total flavonoid contents of approximately 523 to $769 \mathrm{mg}$ QE/g sample.

ABTS and DPPH are tested in the quantitative analysis based on the capability of redox molecules in natural products to scavenge free radicals, which is expressed as the concentration with $50 \%$ ABTS and DPPH radical scavenging effect $\left(\mathrm{IC}_{50}\right)$. The $\mathrm{IC}_{50}$ values of ABTS and DPPH were approximately 1.67 and $3.55 \mathrm{mg} / \mathrm{mL}$ for the crude lipid and 0.21 and $0.43 \mathrm{mg} / \mathrm{mL}$ for the purified lipid (ethyl acetate fraction), respectively. Crude lipid extracts also exhibited $\alpha$-glucosidase inhibitory activity with an $\mathrm{IC}_{50}$ value of $8.97 \mathrm{mg} / \mathrm{mL}$, which could potentially be used in food supplements for preventing diabetes. This result corresponds to those of Sharma and Rhyu [5] and Sharma et al. [6] who found that ethanolic extract from $C$. lentillifera has anti-diabetic potential by causing significant decreases in dipeptidyl peptidase-IV and $\alpha$-glucosidase enzyme activities. Furthermore, this extract has the potential to cause an increase in insulin secretion from rat insulinoma cells and stimulate the glucose uptake in 3T3-L1 adipocytes.

Sabirin et al. [7] reported that the methanolic extract from C. lentillifera possessed antibacterial activity against common causative agents for oral infections, Staphylococcus aureus and Streptococcus mutans. Sharma et al. [40] found that the ethanolic extract of C. okamurae was effective in preventing body weight gain and fat accumulation and reduced plasma and hepatic lipid profiles. Likewise, Rahman et al. [41] reported that the ethanolic extract of C. recemosa could potentially be used as a hypolipemic agent since it exhibited a significant hypolipemic effect at a dose of $200 \mathrm{mg} / \mathrm{kg}$ body weight. Based on this information, lipid extracts from Caulerpa have the potential as a food supplement or agent for good health that might be beneficial for aging societies and people with diabetes or hyperlipidemia. 
Results from this work demonstrate a possible route for sustainable development, and the value of $C$. lentillifera waste can be increased by transformation to a new product, such as a bioactive substance with market value. In addition, the process of lipid extraction from $C$. lentillifera waste is possible for scaling-up in commercial production for three reasons: (1) the extraction uses a simple technique; (2) the crude lipid has potential as an $\alpha$ glucosidase inhibitor; thus, it does not need future purification; and (3) ethanol as a solvent for extraction is safe for human consumption and can be recycled. For the production of C. lentillifera biomass in Thailand, the capacity of fresh biomass in Phetchaburi Province is approximately 25 tons/month based on information from personal communication with the Caulerpa entrepreneur. In case $70 \%$ of biomass is a useless (waste) product, and only $25 \%$ can be reused as propagule, useless biomass is around 11.25 tons/month. Of note, fresh Caulerpa biomass contains approximately 95\% moisture; thus, $562.50 \mathrm{~kg}$ of dried material/month allowed for lipid extraction. Based on these amounts and a $27 \%$ lipid yield, crude lipids of around $150 \mathrm{~kg}$ dried extract/month were obtained. Selling crude lipid as a food supplement could result in more income for farmers.

\section{Conclusions}

The optimum conditions for lipid extraction from C. lentillifera waste consisted of a three-stage extraction (15 min/stage) using a dried algae-to-ethanol ratio of 1:10 $(w / v)$ at room temperature. Under these conditions, a crude lipid yield of around $27.69 \%$ of dry weight was obtained. Since the crude lipid shows the potential for preventing diabetes, it could increase the value of $C$. lentillifera waste and the utilization of algae resources, which could lead to sustainable development.

Author Contributions: Conceptualization, R.C.; investigation, T.S. and N.C.; data curation, R.C.; writing materials and methods, T.S.; writing-review and editing, R.C.; project administration, R.C.; supervisor, B.B. All authors have read and agreed to the published version of the manuscript.

Funding: This work was supported by the Biodiversity-Based Economy Development Office (Public Or-ganization; BEDO) and the National Research Council of Thailand (NRTC) (grant number: BEDO NRTC 25/2019).

Acknowledgments: We would like to thank Khun Montakan Tamtin and Khun Prapat Kosawatpat, Phetchaburi Coastal Aquaculture Research and Development Center, for providing C. lentillifera biomass. We also thank the Algal Biotechnology Research Center, King Mongkut's University of Technology Thonburi, for providing facilities.

Conflicts of Interest: The authors declare no conflict of interest.

\section{References}

1. Ratana-arporn, P.; Chirapart, A. Nutritional evaluation of tropical green seaweeds Caulerpa lentillifera and Ulva reticulate. Nat. Sci. 2006, 40, 75-83.

2. Matanjun, P.; Mohamed, S.; Mustapha, M.N.; Muhammad, K. Nutrient content of tropical edible seaweeds, Eucheuma cottonii, Caulerpa lentillifera and Sargassum polycystum. J. Appl. Phycol. 2009, 21, 75-80. [CrossRef]

3. Nguyen, V.T.; Ueng, J.P.; Tsai, G.J. Proximate composition, total phenolic content, and antioxidant activity of seagrape (Caulerpa lentillifera). J. Food Sci. 2011, 76, C950-C958. [CrossRef]

4. Sarini, A.W.; Nor'Aishah, H.; Mohd Zaini, N. Determination of antioxidant activity for seven types of macroalgae. In Proceedings of the 5th International Conference on Food Engineering and Biotechnology, IPCBEE, Penang, Malaysia, 12-14 March 2014; Volume 65, pp. 51-55.

5. Sharma, B.R.; Rhyu, D.Y. Anti-diabetic effects of Caulerpa lentillifera: Stimulation of insulin secretion in pancreatic $\beta$-cells and enhancement of glucose uptake in adipocytes. Asian Pac. J. Trop. Biomed. 2014, 4, 575-580. [CrossRef]

6. Sharma, B.R.; Kim, H.J.; Rhyu, D.Y. Caulerpa lentillifera extract ameliorates insulin resistance and regulates glucose metabolism in C57BL/KsJ-db/db mice via PI3K/AKT signaling pathway in myocytes. J. Transl. Med. 2015, 13, 1-10. [CrossRef]

7. Sabirin, F.; Kazi, J.A.; Ibrahim, I.; Rashit, M.M.A. Screening of seaweeds potential against oral infections. J. Appl. Sci. Res. 2015, 11, 1-6.

8. West, E.J.; West, R.J. Growth and survival of the invasive alga, Caulerpa taxifolia, in different salinities and temperatures: Implications for coastal lake management. Hydrobiologia 2007, 577, 87-94. [CrossRef]

9. Ukabi, S.; Dubinsky, Z.; Steinberger, Y.; Israel, A. Temperature and irradiance effects on growth and photosynthesis of Caulerpa (Chlorophyta) species from the eastern Mediterranean. Aquat. Bot. 2013, 104, 106-110. [CrossRef] 
10. Gao, X.; Choi, H.G.; Park, S.K.; Sun, Z.M.; Nam, K.W. Assessment of optimal growth conditions for cultivation of the edible Caulerpa okamurae (Caulerpales, Chlorophyta) from Korea. J Appl. Phycol. 2019, 31, 1855-1862. [CrossRef]

11. Chaiklahan, R.; Srinorasing, T.; Chirasuwan, N.; Tamtin, M.; Bunnag, B. The potential of polysaccharide extracts from Caulerpa lentillifera waste. Int. J. Biol. Macromol. 2020, 161, 1021-1028. [CrossRef] [PubMed]

12. Sagar, N.A.; Pareek, S.; Sharma, S.; Yahia, E.M.; Lobo, M.G. Fruit and vegetable waste: Bioactive compounds, their extraction, and possible utilization. Compr. Rev. Food Sci. Food Saf. 2018, 17, 512-531. [CrossRef]

13. Freitas, L.C.; Barbosa, J.R.; da Costa, A.L.C.; Bezerra, F.W.F.; Pinto, R.H.H.; de Carvalho Junior, R.N. From waste to sustainable industry: How can agro-industrial wastes help in the development of new products? Resour. Conserv. Recycl. 2021, $169,105466$. [CrossRef]

14. Galanakis, C.M. Recovery of high added-value components from food wastes: Conventional, emerging technologies and commercialized applications. Trends Food Sci. Technol. 2012, 26, 68-87. [CrossRef]

15. Galanakis, C.M. Emerging technologies for the production of nutraceuticals from agricultural by-products: A viewpoint of opportunities and challenges. Food Bioprod. Process. 2013, 91, 575-579. [CrossRef]

16. Ferri, M.; Vannini, M.; Ehrnell, M.; Eliasson, L.; Xanthakis, E.; Monari, S.; Tassoni, A. From winery waste to bioactive compounds and new polymeric biocomposites: A contribution to the circular economy concept. J. Adv. Res. 2020, 24, 1-11. [CrossRef] [PubMed]

17. Munir, M.; Kheirkhah, H.; Baroutian, S.; Quek, S.Y.; Young, B.R. Subcritical water extraction of bioactive compounds from waste onion skin. J. Clean Prod. 2018, 183, 487-494. [CrossRef]

18. Assefa, S.T.; Yang, E.Y.; Chae, S.Y.; Song, M.; Lee, J.; Cho, M.C.; Jang, S. Alpha glucosidase inhibitory activities of plants with focus on common vegetables. Plants 2020, 9, 2. [CrossRef] [PubMed]

19. Xiancui, L.; Rongli, N.; Xiao, F.; Lijun, H.; Lixin, Z. Macroalgae as a source of alpha-glucosidase inhibitors. Chin. J. Oceanol. Limnol. 2005, 23, 354-356. [CrossRef]

20. Yin, Z.; Zhang, W.; Feng, F.; Zhang, Y.; Kang, W. $\alpha$-Glucosidase inhibitors isolated from medicinal plants. Food Sci. Hum. Wellness 2014, 3, 136-174. [CrossRef]

21. Kumar, S.; Narwal, S.; Kumar, V.; Prakash, O. $\alpha$-glucosidase inhibitors from plants: A natural approach to treat diabetes. Pharmacogn. Rev. 2011, 5, 19-29. [CrossRef]

22. Nguyen, T.T.M.; Nguyen, T.N.; Nguyen, X.H.; Huynh, N.N.T.; Min, S.B. Screening of $\alpha$-glucosidase inhibitory activity of Vietnamese medicinal plants: Isolation of active principles from Oroxylum indicum. Nat. Prod. Sci. 2012, 18, 47-51.

23. Telagari, M.; Hullatti, K. In-vitro $\alpha$-amylase and $\alpha$-glucosidase inhibitory activity of Adiantumcaudatum Linn. and Celosia argentea Linn. extracts and fractions. Indian J. Pharmacol. 2015, 47, 425-429. [PubMed]

24. Yen, F.S.; Wei, J.C.C.; Lin, M.C.; Hsu, C.C.; Hwu, C.M. Long-term outcomes of adding alpha-glucosidase inhibitors in insulintreated patients with type 2 diabetes. BMC Endocr. Disord. 2021, 21, 25. [CrossRef] [PubMed]

25. Bhatia, A.; Singh, B.; Arora, R.; Arora, S. In vitro evaluation of the $\alpha$-glucosidase inhibitory potential of methanolic extracts of traditionally used antidiabetic plants. BMC Complement. Altern. Med. 2019, 19, 74. [CrossRef]

26. Sato, N.; Murata, N. Membrane lipid. Meth. Enzymol. 1988, 167, 251-259.

27. Lapage, G.; Roy, C.C. Improved recovery of fatty acid through direct transesterification without prior extraction of purification. J. Lipid Res. 1984, 25, 1391-1396. [CrossRef]

28. Othman, R.; Amin, N.A.; Sani, M.S.A.; Fadzillah, N.A.; Jamaludin, M.A. Carotenoid and chlorophyll profiles in five species of Malaysian seaweed as potential halal active pharmaceutical ingredient (API). Int. J. Adv. Sci. Eng. Inf. Technol. 2018, 8, 1610-1616.

29. Wu, X.J.; Hansen, C. Antioxidant capacity, phenolic content, and polysaccharide content of Lentinus edodes grown in whey permeate-based submerged culture. J. Food Sci. 2008, 73, M1-M8. [CrossRef] [PubMed]

30. Pallab, K.; Tapan, K.B.; Tapas, K.P.; Ramen, K. Estimation of total flavonoids content (TFC) and antioxidant activities of methanolic whole plant extract of Biophytum sensitivum linn. J. Drug Deliv. Ther. 2013, 3, 33-37.

31. Li, X.; Zhou, A.; Han, Y. Anti-oxidation and anti-microorganism activities of purification polysaccharide from Lygodium japonicum in vitro. Carbohydr. Polym. 2006, 66, 34-42. [CrossRef]

32. Zheleva-Dimitrova, D.; Nedialkov, P.; Kitanov, G. Radical scavenging and antioxidant activities of methanolic extracts from Hypericum species growing in Bulgaria. Pharmacogn. Mag. 2010, 6, 74-78. [CrossRef] [PubMed]

33. Alam, M.A.; Zaidul, I.S.M.; Ghafoor, K.; Sahena, F.; Hakim, M.A.; Rafii, M.Y.; Abir, H.M.; Bostanudin, M.F.; Perumal, V.; Khatib, A. In vitro antioxidant and, $\alpha$-glucosidase inhibitory activities and comprehensive metabolite profiling of methanol extract and its fractions from Clinacanthus nutans. BMC Complement. Altern. Med. 2017, 17, 181-191. [CrossRef]

34. Li, Z.; Wang, B.; Zhang, Q.; Qu, Y.; Xu, H.; Li, G. Preparation and antioxidant property of extract and semipurified fractions of Caulerpa racemose. J. Appl. Phycol. 2012, 24, 1527-1536. [CrossRef]

35. Chirasuwan, N.; Chaiklahan, R.; Kittakoop, P.; Chanasattru, W.; Ruengjitchatchawalya, M.; Tanticharoen, M.; Bunnag, B. Anti HSV-1 activity of sulphoquinovosyl diacylglycerol isolated from Spirulina platensis. Sci. Asia 2009, 35, 137-141. [CrossRef]

36. Blažina, M.; Iveša, L.; Najdek, M. Caulerpa racemosa: Adaptive varieties studied by fatty acid composition (Northern Adriatic Sea, Vrsar, Croatia). Eur. J. Phycol. 2009, 44, 183-189. [CrossRef]

37. Yap, W.F.; Tay, V.; Tan, S.H.; Yow, Y.Y.; Chew, J. Decoding antioxidant and antibacterial potentials of Malaysian green seaweeds: Caulerpa racemosa and Caulerpa lentillifera. Antibiotics 2019, 8, 152. [CrossRef] 
38. Osuna-Ruiz, I.; López-Saiz, C.M.; Burgos-Hernández, A.; Velázquez, C.; Nieves-Soto, M.; Hurtado-Oliva, M.A. Antioxidant, antimutagenic and antiproliferative activities in selected seaweed species from Sinaloa, Mexico. Pharm. Biol. 2016, 54, $2196-2210$. [CrossRef]

39. Tanna, B.; Choudhary, B.; Mishra, A. Metabolite profiling, antioxidant, scavenging and anti-proliferative activities of selected tropical green seaweeds reveal the nutraceutical potential of Caulerpa spp. Algal Res. 2018, 36, 96-105. [CrossRef]

40. Sharma, B.R.; Kim, H.J.; Kim, M.S.; Park, C.M.; Rhyu, D.Y. Caulerpa okmurae extract inhibits adipogenesis in 3T3-L1 adipocytes and prevents high-fat diet-induced obesity in C57BL/ 6 mice. Nutr. Res. 2017, 47, 44-52. [CrossRef]

41. Rahman, S.M.; Neaz, S.; Alam, M.M.; Nur, J. Hypolipidemic activity of ethanolic extract of Caulerpa recemosa. BIRDEM Med. J. 2019, 9, 197-201. [CrossRef] 